\title{
The Effects of Exposure to Low Frequency Electromagnetic Fields in the Treatment of Migraine Headache: A Cohort Study
}

\author{
Seyed Ehsan Mohammadianinejad ${ }^{1}$, Manuchehr Babaei ${ }^{2}$, Pedram Nazari ${ }^{3}$
}

${ }^{1}$ M.D., Neurologist, Assistant Professor, Department of Neurology, Ahvaz Jundishapur University of Medical Sciences, Ahvaz, Iran

${ }^{2}$ Neurology Resident, Department of Neurology, Ahvaz Jundishapur University of Medical Sciences, Ahvaz, Iran

${ }^{3}$ Medical Student, Student Research Committee, Ahvaz Jundishapur University of Medical Sciences, Ahvaz, Iran

\section{Type of article: Original}

\begin{abstract}
Introduction: Findings have indicated that increased usage of mobile phones may be concomitant with higher rate of headache attacks due to the low radiofrequency electromagnetic fields (RF-EMF). The aim of this study was to determine the effects of low RF-EMF on the treatment outcome in migraine patients.

Methods: This cohort study was performed on 114 migraine patients referred to the Neurology Clinic of Golestan Hospital in Ahvaz, Southwest Iran, from September 2014 to March 2015. Patients with migraine were interviewed using a standardized questionnaire exploring mobile phones, Wi-Fi devices and fixed-line telephone use as RF-EMF sources. After 3 months, we determined patients' response to treatment. Generalized estimating equation (GEE) tests were carried out to analyze data, using SPSS version 17.

Results: Out of 114 individuals who participated, 82 (71.9\%) were female and $32(28.1 \%)$ cases were male. The number and severity of migraine headaches were correlated significantly with an increased use of mobile phones during day and Wi-Fi per week $(\mathrm{p}<0.05)$. The usage of fixed-line telephones had no significant relationship with the study variables $(\mathrm{p}>0.05)$.

Conclusion: It is recommended that the patients with migraine headache limit mobile phone use and instead, use the fixed-line telephone for their daily telecommunications.

Keywords: Radio frequency, Electromagnetic field, Mobile phone, Headache, Migraine Wi-Fi
\end{abstract}

\section{Introduction}

Migraine is one of the most common causes of headaches. Its prevalence is $17 \mathrm{vs.} 6 \%$ for women and men, respectively (1). Usually, its severity affects daily performance capabilities and function of individuals (2). Although, several studies have been carried out to explain pathophysiologic mechanism in migraine, it has, in general remained an enigma However, most researchers believe that the disturbance of the neuro-electrical activity related to brain cells, increases the sensitivity of the cerebral cortex and brain vascular changes with potential genetic susceptibility factors, and plays an important role in migraine headache (3). To initiate and accelerate these events some environmental and behavioral factors act as a potent trigger for migraine attacks (3). Recently, an epidemiologic study indicated a higher occurrence of migraine attacks in mobile users (4). The matter has created genuine concern regarding the extensive exposure of individuals to radiofrequency electromagnetic fields (RFEMF), due to the worldwide comprehensive expanse of mobile telecommunication technology (5). There are some suggested hypotheses that the electromagnetic waves affect various aspects of human physiology by interaction with cellular electromagnetic events (6). One of the most important alterations induced by electromagnetic fields is the disturbance in brain function because of the close contact of these devices to the head (7). Previous studies have shown that these waves influence regional cerebral blood flow and electroencephalographic (EEG) wave power (7). Also, some people have claimed that they had electromagnetic hypersensitivity and experience some symptoms such

\section{Corresponding author:}

Dr. Manuchehr Babaei, Department of Neurology, Ahvaz Jundishapur University of Medical Sciences, Ahvaz, Iran. Tel: +989133108820, Fax: +986133743012, Email: ali4954@yahoo.com

Received: May 05, 2016, Accepted: July 20, 2016, Published: December 2016

iThenticate screening: July 10, 2016, English editing: September 14, 2016, Quality control: October 27, 2016

(C) 2016 The Authors. This is an open access article under the terms of the Creative Commons Attribution-NonCommercialNoDerivs License, which permits use and distribution in any medium, provided the original work is properly cited, the use is non-commercial and no modifications or adaptations are made. 
as headache, tinnitus, sleep disorders and other neurological complaints when exposed to these fields. Overall, headache is the most frequent symptom induced by RF-EMF (8). Based on the mentioned facts, RF-EMF can be regarded as a probable environmental trigger for migraine headaches. Such issues will raise the question of what the potential effect of this environmental risk factor would be, on the patients' response to treatment regimens. To the best of our knowledge, there was no study to investigate the effects of RF-EMF on the treatment response in migraine individuals. Therefore, we designed this study to determine the effects of RF-EMF on therapeutic response of migraine headache patients.

\section{Material and Methods}

\subsection{Research design}

This cohort study was performed on migraine patients referred to the Neurology Clinic of Golestan Hospital, located in Ahvaz, Southwest Iran, from September 2014 to March 2015.

\subsection{Sampling}

The sample size was calculated to be 114 subjects, based on the reference number 12 and using the following formula (with PASS software): $\mathrm{n}=(\mathrm{Z} 1-\alpha / 2+\mathrm{Z} 1-\beta)^{2} \times\left((\mathrm{P} 1 \times(1-\mathrm{P} 1)+\mathrm{P} 2 \times(1-\mathrm{P} 2)) /(\mathrm{P} 1-\mathrm{P} 2)^{2}\right.$; Where: $\mathrm{n}=$ Sample size, $Z 1-\alpha / 2=1.96$ when $\alpha=5 \%, Z 1-\beta=0.842$ when $\beta=20 \%, P=$ Probability of the main outcome.

\subsection{Selection criteria}

The inclusion criteria were considered patients with confirmed migraine based on the International Headache Society (IHS) criteria of the headache classification, without other serious and or chronic diseases (9). Furthermore, workers in high levels of RF-EMF were excluded.

\subsection{Instrument}

Authors designed the appropriate questionnaire, with a view to exploring whether the individuals used mobile phone, Wi-Fi devices and fixed-line telephone as RF-EMF sources. The questionnaire was organized into three sections, including: 1, Personality identifier, 2, The rate of exposure to RF-EMF sources (mobile phone, Wi-Fi devices, fixed-line telephone and cordless phone's) as well as the distance between mobile phone and the subject's head during night sleep, and 3, The frequency and severity of migraine headaches and the particular incident which triggered the headache, if any. The content validity of this checklist was confirmed by five expert neurologists. Also, the questionnaire showed good reliability with Cronbach's alpha coefficient equal to 0.81 .

\subsection{Data collection and other methods}

A total of 114 individuals were randomly selected. Patients were categorized into three groups (mild, moderate, severe) based on severity and frequency of migraine headache according to IHS classification (10). Then suitable treatment was administered according to the guideline advised by expert neurologists (11). Participants were interviewed using a standardized questionnaire at the beginning of the study. We retrieved the factory reported specific absorption rate (SAR) of all patients' mobile phones, based on the brand and model of each phone. We asked the patients to report the estimated number of days per week of being close to a known Wi-Fi source in their home or work place. Also, the patients reported the distance between mobile phone and their head during night sleep (more or less than 1 meter) and the mean duration of mobile phone and fixed-line telephone use (minutes per day) based on usage-charge that they had paid to the national telecommunication service providers over the last month. Moreover, we asked them about the frequency and severity of migraine headaches (based on a visual analog scale). We monitored the patients according to drug compliance, response to treatment and adherence to study with monthly follow-up and face to face interview. After 3 months, we asked each subject questions and compared all parameters with the base line. Also, we assayed some confounding factors such as having flu or cold, and behavioral or sleep habit changes among patients during this interval period (12).

\subsection{Statistical analysis}

The collected data were analyzed using SPSS version 17 (SPSS Inc., Chicago, Illinois, USA). Descriptive statistics were used, to describe the quantitative variables of the data. The GEE (Generalized Estimation Equation) was used to detect the effects of different variables on number of headache, number of mild, moderate and severe headaches, number of migraine attacks and the severity of headaches. 


\subsection{Ethical consideration}

The Ethics Committee of Ahvaz Jundishapur University of Medical Sciences approved the study. Also, in accordance with the provisions of the Declaration of Helsinki, before the start of the study, voluntary and informed consent was obtained from all participants.

\section{Results}

Overall, 114 individuals participated of which 82 (71.9\%) were female and $32(28.1 \%)$ cases were male, . The mean age was $30 \pm 9.8$ years with age range from $15-50$ years. Most of participants (90.4\%) were from urban areas. Based on disease severity $29(25.4 \%)$ patients were treated with Nortriptyline and Propranolol, 35 (30.70\%) with Propranolol, 35 (30.70\%) with Acetaminophen, and 15 (13.2\%) patients received Nortriptyline. The expectation of the number of headaches, the number of mild, moderate and severe headaches, the number of migraine attacks and the severity of headaches decreased significantly at the end of the study. Chi-square test showed that the different levels of Wi-Fi usage were the same in different categories of drugs $(p=0.7)$ (Table1). The average mobile use, SAR was also equal in the categories of drugs. ANOVA tests confirmed that the p-values were $0.5,0.12,0.35,0.42$ and 0.08 respectively. A total of 46 participants did not use Wi-Fi, while $32(28.1 \%)$ cases used one to four days per week, and eighteen (15.8\%) of the participants used Wi-Fi most of the days. The chance of increasing number of headaches and the level of severity of headache for persons who had high use of Wi-Fi were significantly higher than the persons with low use of Wi-Fi. The use of Wi-Fi had no significant effect on the number of migraine attacks. Most patients $(\mathrm{n}=112,98.30 \%)$ used a mobile phone with median time equal to $58.57 \mathrm{~min}$ call (0-360 min). Increase of mobile usage had a significant effect on the number of moderate headaches and the number of migraine attacks, and severity of headache. One more minute of mobile use, enhanced the possibility of a moderate headache and the number of migraine attacks $0.2 \%$, and also increased the chance of level of severity $0.1 \%$. Sixty individuals $(52.6 \%)$ reported that the distance of mobile phone to their head was less 1 meter, during night sleep. It had no correlation with severity and frequency of migraine headaches and treatment outcome ( $>>0.05)$. Overall, 111 (37.97\%) patients used fixed-line telephones during the day with average use $53.29 \pm 41.72$ min per day. The usage of fixed-line telephone had no significant relationship with study variables $(\mathrm{p}>0.05)$.

Table 1. The mean changes of headache severity in migraine participants receiving treatment in the last 3 months

\begin{tabular}{|c|c|c|c|c|c|c|}
\hline \multirow[t]{2}{*}{ Parameter } & \multicolumn{6}{|l|}{ Odds ratio } \\
\hline & $\begin{array}{l}\text { Number of } \\
\text { Headache }\end{array}$ & $\begin{array}{l}\text { Number of } \\
\text { Mild } \\
\text { Headache }\end{array}$ & $\begin{array}{l}\text { Number of } \\
\text { Moderate } \\
\text { Headache }\end{array}$ & $\begin{array}{l}\text { Number of } \\
\text { Severe } \\
\text { Headache }\end{array}$ & $\begin{array}{l}\text { Number of } \\
\text { Migraine } \\
\text { Attack }\end{array}$ & Severity \\
\hline (Intercept) & 4.17 & 9.43 & 3.95 & 3.23 & 2.68 & 4.90 \\
\hline$[\mathrm{Wi}-\mathrm{Fi}=1.00] \mathrm{a}$ & $0.65^{*}$ & $0.64^{*}$ & $0.63 *$ & $0.61 *$ & 1.03 & $0.76^{*}$ \\
\hline$[\mathrm{Wi}-\mathrm{Fi}=2.00] \mathrm{b}$ & $0.67 *$ & $0.65 *$ & $0.65 *$ & $0.65 *$ & 0.95 & $0.76^{*}$ \\
\hline$[\mathrm{Wi}-\mathrm{Fi}=3.00] \mathrm{c}$ & 1 & 1 & 1 & 1 & 1 & 1 \\
\hline $\begin{array}{l}\text { Baseline of the } \\
\text { study }\end{array}$ & $1.36^{*}$ & $1.47 *$ & $1.23 *$ & $1.21 *$ & $1.6^{*}$ & $1.30 *$ \\
\hline End of the study & 1 & 1 & 1 & 1 & 1 & 1 \\
\hline Mobile Usage & 1.001 & 1.00 & $1.002 *$ & 1.001 & $1.002 *$ & $1.001 *$ \\
\hline $\begin{array}{l}\text { Distance between } \\
\text { mobile phone and } \\
\text { users head }\end{array}$ & 1.14 & 1.12 & 1.10 & 1.24 & 1.03 & 0.98 \\
\hline SAR & 0.74 & 0.95 & 1.005 & 0.89 & 1.10 & 1.055 \\
\hline Computer usage & 1.001 & 1.001 & 1.002 & 1.002 & 1.001 & 1.001 \\
\hline
\end{tabular}

\section{Discussion}

Currently, the growing number of telecommunication devices such as mobile phones and Wi-Fi have led people to increased exposure to RF-EMF (12). This matter had raised challenging questions. From these inquiries, the important problem is clarifying whether these electromagnetic waves that emitted from mobile phone and Wi-Fi antenna cause side effects on our body, and especially the CNS. These concerns have originated from some studies that have shown notable evidence of RF-EMF effects on brain tissues (13). Unfortunately, the answers to these questions remain unclear, but some evidence supports the adverse effects of RF-EMF on some neurological symptoms. Based on our result, we found significant correlation among mobile phone and Wi-Fi usage with more frequency and severity of migraine headaches. In agreement to our findings, several studies had shown that more 
mobile phone use was concordance with increasing rate of migraine headaches, tinnitus, and fatigue (10). Redmayne et al. showed that Wi-Fi use could be associated with sleep disturbance (12). The previous studies implicated that the electromagnetic waves spectrum of Wi-Fi could increase the power of alpha waves during sleep (14). This information suggest that extrinsic RF-EMFs can impact neurological functions. There are attractive theories for explanations of related mechanism. In accordance with the Tsong hypothesis, RF-EMF can be introduced as language of cells (15). We suppose that interaction between the external source of RF-EMF, and RF-EMF emitted normally from the brain cells, leads to dopamine-opioid system disturbances, as well as the blood brain barrier involvement (16). This mechanism explains some well-known pathophysiological processes involved in migraine headaches based on the dopaminergic system (17).

In contrary to our findings, Berg-Beckhoff et al. demonstrated RF-RMs emitted from mobile phones had no adverse health effects (18). Additionally, most mobile phone and Wi-Fi users usually have more stress, and the stress is an important trigger for migraine headaches. Now, a difficult question arises. Is this effect contributed to more exposure with RF-EMF, or due to the stress effect per se (19)? In fact, the answers are controversial; however, some researchers proposed restriction of the unnecessary exposure to any RF-EMF sources, until arriving at a clear answer to this question (16). There is a completely contrary view to our study. In accordance to this view, Sherman et al. applied pulsing electromagnetic fields (PEMF) as a migraine treatment in a double-blind, placebo-controlled study. They demonstrated that actual exposure of the inner thigh to PEMF over a three week period, led to decreased headache and acted as an effective intervention for migraine treatment. Researchers attributed these effects to increased peripheral blood, induced by PEMF. We suppose these differences are due to the different frequency of waves used in the two studies (20). The frequency of waves used for PEMF was significantly less than mobile phone and Wi-Fi modems. It seems that EMF had dual effects, based on some properties such as frequency of waves and exposure duration (20). Current study is the first investigation performed on the effects of RF-EMF on the treatment outcome in migraine headache patients. We believe that present research is the beginning of a new approach as the first step. However, our study had some limitations due to confounding factors. Firstly, we had no sufficient equipment to design our investigation based on dosimetry methods. Secondly, our data collection relies on selfreported questionnaires.

\section{Conclusions}

Our study showed that the number and severity of migraine headaches were concomitant with more use of mobile phone during the day and Wi-Fi per week. These findings indicated that some RF-EMF may be correlated with more severe migraine headaches. It is recommended that patients with migraine headaches restrict using mobile phone and Wi-Fi and replace them with a fixed-line telephone for their daily telecommunications. We advise other researchers to continue without the limitations that we had and based on dosimetry methods and provocation protocol.

\section{Acknowledgments:}

The study was a postgraduate thesis of Dr. Manuchehr Babaei supported financially by the Vice-Chancellor for Research and Technology, Ahvaz Jundishapur University of Medical Sciences (grant number, U-93099). Authors would like to express their gratitude to Dr. Seyed Aidin Sajedi, for his kind support and comments.

\section{Conflict of Interest:}

There is no conflict of interest to be declared.

\section{Authors' contributions:}

All authors contributed to this project and article equally. All authors read and approved the final manuscript.

\section{References:}

1) Stewart WF, Wood C, Reed ML, Roy J, Lipton RB; AMPP Advisory Group. Cumulative lifetime migraine incidence in women and men. Cephalalgia. 2008; 28(11): 1170-8. doi: 10.1111/j.1468-2982.2008.01666.x. PMID: 18644028.

2) Derry CJ, Derry S, Moore RA. Sumatriptan (all routes of administration) for acute migraine attacks in adults - overview of Cochrane reviews. Cochrane Database Syst Rev. 2014; (5): CD009108. doi: 10.1002/14651858.CD009108.pub2. PMID: 24865446. 
3) Villaln C, Centurin D, Valdivia L, de Vries P, Saxena PR. Migraine: pathophysiology, pharmacology, treatment and future trends. Curr Vasc Pharmacol. 2003; 1(1): 71-84. doi: 10.2174/1570161033386826. PMID: 15320857.

4) Schüz J, Waldemar G, Olsen JH, Johansen C. Risks for central nervous system diseases among mobile phone subscribers: a Danish retrospective cohort study. PLoS One. 2009; 4(2): e4389. doi: 10.1371/journal.pone.0004389. PMID: 19194493, PMCID: PMC2632742.

5) Grad FP. The preamble of the constitution of the World Health Organization. Bull World Health Organ. 2002; 80(12): 981-4. doi: 10.1590/S0042-96862002001200014. PMID: 12571728, PMCID: PMC2567708.

6) Cifra M, Fields JZ, Farhadi A. Electromagnetic cellular interactions. Prog Biophys Mol Biol. 2011; 105(3): 223-46. doi: 10.1016/j.pbiomolbio.2010.07.003. PMID: 20674588.

7) Huber R, Treyer V, Borbély AA, Schuderer J, Gottselig JM, Landolt HP, et al. Electromagnetic fields, such as those from mobile phones, alter regional cerebral blood flow and sleep and waking EEG. J Sleep Res. 2002; 11(4): 289-95. doi: 10.1046/j.1365-2869.2002.00314.x. PMID: 12464096.

8) Oftedal G, Straume A, Johnsson A, Stovner LJ. Mobile phone headache: a double blind, sham-controlled provocation study. Cephalalgia. 2007; 27(5): 447-55. doi: 10.1111/j.1468-2982.2007.01336.x. PMID: 17359515.

9) Headache Classification Committee of the International Headache Society (IHS). The International Clasification of Headache Disorders, 3rd edition (beta version). Cephalalgia. 2013; 33(9): 629-808. doi: 10.1177/0333102413485658. PMID: 23771276.

10) Chia SE, Chia HP, Tan JS. Prevalence of headache among handheld cellular telephone users in Singapore: a community study. Environ Health Perspect. 2000; 108(11): 1059-62. doi: 10.2307/3434959. PMID: 11102297, PMCID: PMC1240163.

11) Tfelt-Hansen PC. Evidence-based guideline update: pharmacologic treatment for episodic migraine prevention in adults: report of the Quality Standards subcommittee of the American Academy of Neurology and the American Headache Society. Neurology. 2013; 80(9): 869-70. doi: 10.1212/01.wnl.0000427909.23467.39. PMID: 23439705.

12) Redmayne M, Smith E, Abramson MJ. The relationship between adolescents' well-being and their wireless phone use: a cross-sectional study. Environ health. 2013; 12: 90. doi: 10.1186/1476-069X-12-90. PMID: 24148357, PMCID: PMC4015920.

13) Dimbylow PJ, Mann SM. SAR calculations in an anatomically realistic model of the head for mobile communication transceivers at $900 \mathrm{MHz}$ and $1.8 \mathrm{GHz}$. Phys Med Biol. 1994; 39(10): 1537-53. doi: 10.1088/0031-9155/39/10/003. PMID: 15551530.

14) Mann K, Röschke J. Sleep under exposure to high-frequency electromagnetic fields. Sleep Med Rev. 2004; 8(2): 95-107. doi: 10.1016/S1087-0792(03)00004-2. PMID: 15033149.

15) Tsong TY. Deciphering the language of cells. Trends Biochem Sci. 1989; 14(3): 89-92. doi: 10.1016/09680004(89)90127-8. PMID: 2728105.

16) Frey AH. Headaches from cellular telephones: are they real and what are the implications? Environ Health Perspect. 1998; 106(3): 101-3. doi: 10.2307/3434310. PMID: 9441959, PMCID: PMC1533043.

17) Stam AH, Haan J, van den Maagdenberg AM, Ferrari MD, Terwindt GM. Migraine and genetic and acquired vasculopathies. Cephalalgia. 2009; 29(9): 1006-17. doi: 10.1111/j.1468-2982.2009.01940.x. PMID: 19689610.

18) Berg-Beckhoff G, Blettner M, Kowall B, Breckenkamp J, Schlehofer B, Schmiedel S, et al. Mobile phone base stations and adverse health effects: phase 2 of a cross-sectional study with measured radio frequency electromagnetic fields. Occup Environ Med. 2009; 66(2): 124-30. doi: 10.1136/oem.2008.039834. PMID: 19151228.

19) Wilen J, Sandström M, Hansson Mild K. Subjective symptoms among mobile phone users-a consequence of absorption of radiofrequency fields? Bioelectromagnetics. 2003; 24(3): 152-9. doi: 10.1002/bem.10101. PMID: 12669297.

20) Sherman RA, Acosta NM, Robson L. Treatment of migraine with pulsing electromagnetic fields: A double blind, placebo controlled study. Headache. 1999; 39(8): 567-75. doi: 10.1046/j.1526-4610.1999.3908567.x. PMID: 11279973. 